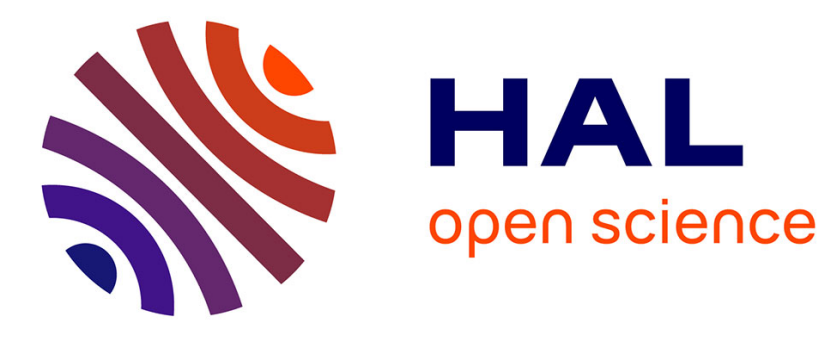

\title{
Control of DNA integrity in skeletal muscle under physiological and pathological conditions
}

Yara Bou Saada, Vlada Zakharova, Boris Chernyak, Carla Dib, Gilles Carnac, Svetlana Dokudovskaya, Yegor Vassetzky

\section{- To cite this version:}

Yara Bou Saada, Vlada Zakharova, Boris Chernyak, Carla Dib, Gilles Carnac, et al.. Control of DNA integrity in skeletal muscle under physiological and pathological conditions. Cellular and Molecular Life Sciences, 2017, 74 (19), pp.3439 - 3449. 10.1007/s00018-017-2530-0 . hal-01826913

\section{HAL Id: hal-01826913 \\ https://hal.umontpellier.fr/hal-01826913}

Submitted on 12 Dec 2019

HAL is a multi-disciplinary open access archive for the deposit and dissemination of scientific research documents, whether they are published or not. The documents may come from teaching and research institutions in France or abroad, or from public or private research centers.
L'archive ouverte pluridisciplinaire HAL, est destinée au dépôt et à la diffusion de documents scientifiques de niveau recherche, publiés ou non, émanant des établissements d'enseignement et de recherche français ou étrangers, des laboratoires publics ou privés. 


\title{
Control of DNA integrity in skeletal muscle under physiological and pathological conditions
}

\author{
Yara Bou Saada ${ }^{1}$ Vlada Zakharova ${ }^{1,2}$ - Boris Chernyak ${ }^{2}$. \\ Carla Dib $^{1}$ - Gilles Carnac ${ }^{3}$ - Svetlana Dokudovskaya ${ }^{1}$. \\ Yegor S. Vassetzky ${ }^{1,2,4}$ iD
}

\begin{abstract}
Skeletal muscle is a highly oxygen-consuming tissue that ensures body support and movement, as well as nutrient and temperature regulation. DNA damage induced by reactive oxygen species is present in muscles and tends to accumulate with age. Here, we present a summary of data obtained on DNA damage and its implication in muscle homeostasis, myogenic differentiation and neuromuscular disorders. Controlled and transient DNA damage appears to be essential for muscular homeostasis and differentiation while uncontrolled and chronic DNA damage negatively affects muscle health.
\end{abstract}

Keywords DNA damage · DNA repair · Oxidative stress · Aging

\section{Introduction}

DNA damage is a part of the daily life of a living organism, and the capacity of the organism to detect and repair DNA damage ensures health and survival. DNA integrity is

Yegor S. Vassetzky

vassetzky@igr.fr

UMR 8126, CNRS, Univ. Paris-Sud, Université Paris Saclay, Institut de Cancérologie Gustave-Roussy, 94805 Villejuif, France

Belozersky Institute of Physico-Chemical Biology, Lomonosov Moscow State University, Moscow 117334, Russia

PhyMedExp, INSERM U1046, CNRS UMR 9214, University of Montpellier, 34295 Montpellier Cedex 5, France

Koltzov Institute of Developmental Biology, Moscow 117334, Russia essential for a living cell to maintain its survival and growth. Tens of thousands of spontaneous modifications per day occur in DNA of a single human cell (for review see $[1,2])$. They are mainly due to endogenous genotoxic sources related to DNA replication and repair as well as free radicals which can oxidatively damage DNA. Skeletal muscles are subjected to DNA damage by exposure to endogenous and exogenous genotoxic sources. Reactive oxygen species (ROS) are thought to be a major cause of DNA damage in skeletal muscles. ROS in muscles are generated during cellular metabolism, muscle contraction, hypoxia, inflammation and muscle regeneration. In this review, we discuss the major sources of DNA damage in skeletal muscles, the consequences of DNA damage and oxidative stress in muscle physiology and in myopathies.

\section{Oxidative stress}

Reactive oxygen species represent a group of highly reactive molecules with oxidizing properties. The incomplete reduction of $\mathrm{O}_{2}$ generates ROS with a high oxidizing potential: the superoxide radical $\left(\mathrm{O}_{2}{ }^{-}\right)$, hydrogen peroxide $\left(\mathrm{H}_{2} \mathrm{O}_{2}\right)$ and the hydroxyl radical $\left(\mathrm{OH}^{-}\right)$; they are products of $\mathrm{O}_{2}$ reduction by one, two, or three electrons, respectively. Cells constantly produce ROS; in fact, any controlled enzymatic reaction involving electron transfer can lead to electron leakage which produces ROS in the presence of $\mathrm{O}_{2}$.

Respiratory chain of mitochondria catalyzes electron transfer to oxygen and a partial reduction of $\mathrm{O}_{2}$; this can generate ROS [3]. Muscle contraction increases oxygen consumption. This oxygen is further reduced to $\mathrm{H}_{2} \mathrm{O}[4,5]$. At the same time, from 0.15 to $5 \%$ of $\mathrm{O}_{2}$ is converted to superoxide radical [5-7]. Thus, mitochondria are an important source of ROS in skeletal muscle. Other 
pathways also lead to generation of ROS. These pathways involve xanthine oxidase (XO) [8, 9], lipoxygenases (LOX) $[6,10]$ and nicotinamide adenine dinucleotide phosphate (NADPH) oxidase (NOX) $[6,8,11]$.

Overproduction of ROS can occur under physiological conditions and participate in normal biological processes such as signal transduction, cellular response against infections, cell proliferation, apoptosis and stimulation of antioxidant systems (for review, see [12]). ROS produced above certain limits can damage proteins, lipids, nucleotides, RNA and DNA. To avoid intracellular accumulation of ROS and to maintain cellular homeostasis, several enzymatic $[13,14]$ and non-enzymatic [15-19] cellular antioxidant defense systems can be activated in a coordinated manner to prevent or reduce oxidative damage. Oxidative stress occurs when redox homeostasis is impaired in the cell; this imbalance may be due to overproduction of ROS or deficiency of the antioxidant system. Non-physiological production of ROS may be the result of cellular metabolism dysfunction or exposure to an exogenous pro-oxidative source such as ionizing radiation, ultraviolet radiation, inflammation and stimulation of the immune system. For example, stimulation of the immune system leads to local and massive production of ROS partially due to stimulation of NADPH oxidase activity in phagocytes (for review see [20]). Inflammation resulting from a chronic infection generates ROS via recruited neutrophils which produce superoxide radicals and $\mathrm{H}_{2} \mathrm{O}_{2}$ [21]. An antioxidant system deficiency, including deregulation in the synthesis of glutathione or antioxidant enzymes [22] or a decrease in the stock of antioxidant vitamins [23], leads to an increase of intracellular ROS. Excessive ROS accumulation may cause irreversible damage to cellular macromolecules and consequently lead to apoptosis [24] or carcinogenesis [25]. ROS may also oxidize and alter the pool of nucleotides, thus influencing genomic integrity (for review see [26]). Importantly, several diseases are characterized by high levels of ROS including Type 2 diabetes and Alzheimer's disease. Indeed, hyperglycemia stimulates ROS production from NADPH oxidases [27], glucose auto-oxidation [28], xanthine oxidase [29] and others. Patients suffering from Alzheimer's disease accumulate high levels of amyloid-B-peptide in their brain; this peptide interacts with copper and generates $\mathrm{Cu}^{+}$from $\mathrm{Cu}^{2+}$ due to its $\mathrm{Cu}$-reductase activity, thus producing hydrogen peroxide as a by-product [30]. Increased oxidative stress in patients' brain has been correlated with increased DNA and protein oxidation and lipid peroxidation [31]; this damage participates in the development of Alzheimer's disease.

\section{Oxidative stress and muscle homeostasis}

Reactive oxygen species production is a prominent event during muscle contraction. ROS affect the function and health of skeletal muscle. ROS are generated in multiple compartments within the muscle cell; mitochondria, sarcoplasmic reticulum, and transverse tubular sarcolemma (for review, see [6]). However, the source of ROS may also be external to the muscle cells; e.g., phagocytic cells may produce ROS after muscle injury. ROS were consudered to be toxic toxic to the muscle tissue. Now it appears that low concentrations of ROS participate in the physiological regulation of muscle. Indeed, ROS participate and trigger signaling pathways causing either "positive" responses such as muscle adaptation or "negative" responses including cell damage and death. This duality given to ROS is mainly dependent on their concentration and on time of exposure, but also on the efficiency of the antioxidant system and the capacity to repair cellular DNA.

\section{Physiological roles of ROS in skeletal muscles}

During moderate exercise, ROS act as signaling molecules and activate several signaling pathways including $\mathrm{NF}-\kappa \mathrm{B}$ (nuclear factor- $\kappa \mathrm{B}$ ) and AP-1 pathways, which directly stimulate the expression of several antioxidants genes such as $S O D$ and $G P X$ [32]. In addition, ROS stimulate expression of IGF-1 (insulin-like growth factor 1), a growth factor crucial for muscle growth [33]. Also, ROS appear to be essential for the muscle strength $[34,35]$. This physiological response to ROS production reflects muscle adaptation to physical exercise. ROS released by phagocytic cells recruited to a damaged muscle site are important for the regeneration of muscle fibers [36].

ROS also influence the morphology, function and biogenesis of mitochondria [37, 38], an essential organelle for energy metabolism and muscle function. In fact, ROS produced above the physiological level, e.g., following a physical training, activate signaling pathways [39, 40]. This leads to expression of nuclear genes encoding mitochondrial proteins, genes necessary for the activation of transcription and replication of both mitochondrial DNA [41], and genes involved in mitochondrial (Mn-SOD) and cytosolic (CAT and GPX) antioxidant defense.

Muscle growth is a costly process restricted to optimal nutrient and energy availability. The central regulator of the eukaryotic cell growth and response to the variety of signals, including nutrients and oxygen, is the highly conserved mammalian target of rapamycin complex 1 (mTORC1) [42]. Mammalian TORC1 is a critical signaling complex that regulates muscle mass. For example, in mice, 
muscle-specific loss of mTORC1 reduces muscle mass and oxidative function and leads to early death [43]. The reduction of muscle weight is a common effect in cancer patients, especially those that are treated with mTORC1 inhibitors, rapamycin and rapalogs. At the same time, rapamycin has been shown to consistently increase the lifespan in many model organisms. In particular, a significant decrease in the amount and function of muscle mitochondria was detected upon life-long high protein diet in mice which was reverted by chronic treatment with rapamycin [44].

Among many functions exerted by mTORC1, one of the most complex ones involves regulation of mitochondrial homeostasis. mTORC1 is essential for mitochondrial biogenesis, phosphorylation of mitochondrial proteins and regulation of selective degradation of mitochondria by autophagy and mitophagy [45]. Under favorable conditions, mTORC1 stimulates mitochondrial biogenesis via transcriptional regulation of a number of mitochondrial genes. Remarkably, mTORC1 activity is induced by low level of ROS, while high ROS levels lead to its inhibition [46]. ROS probably activate mTORC1 via oxidation of cysteine groups either in the mTORC1 complex itself [47] or in some of its upstream regulators [48]. In addition, one of mTORC1 upstream regulators, Sestrin 2, has an antioxidant function that suppresses ROS [49]. Sestrin 2 may function as a direct scavenger for ROS [50] and is also involved in the regulation of mitochondria respiration [51]. Overall, the inactivation of mTORC1 by ROS represents a feedback mechanism, since it leads to reduction of mitochondria via mitophagy and thus prevents further increases in ROS formation. Taken together, these findings demonstrate that skeletal muscle adaptation to ROS production is important for the energy metabolism and mitochondrial biogenesis (Fig. 1).

Fig. 1 Physiological and pathological roles of ROS and DNA damage in muscle

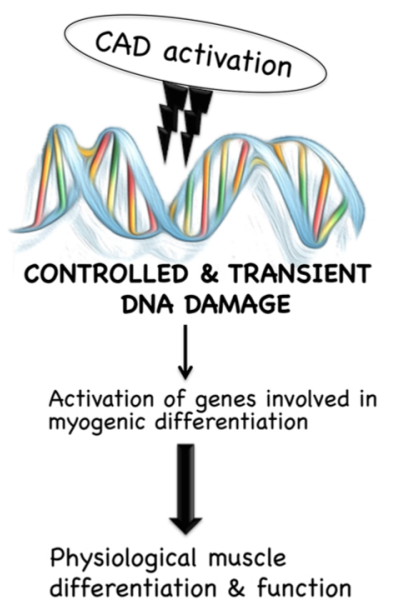

\section{Pathological effects of oxidative stress on skeletal} muscles

Oxidative stress is a major contributor to aging. Indeed, ROS can affect skeletal muscles health and aging; they can reduce the efficiency of myogenic differentiation. An excess in ROS production alters mitochondria necessary for the myogenic differentiation [52]. Besides oxidative damage to mitochondrial DNA, ROS can also cause mitochondrial fragmentation and alteration of mitochondrial permeability facilitating the release of cytochrome $c$, which triggers apoptosis (for review see [53]). Oxidative stress can also promote autophagy by stimulating the maturation of autophagosomes [54], as well as mitophagy [55]. Interestingly, mitochondrial ROS can change the fate of muscle precursor cells (satellite cells) by promoting their transdifferentiation into adipocytes [56]. This may contribute to muscle aging.

ROS can also affect muscle regeneration. Besides the flow of ROS produced by skeletal muscle cells in response to various internal and external stimuli, ROS can be generated by non-muscle cells. Indeed, ROS produced by inflammatory cells after a muscle injury followed by a local inflammation are involved in the regeneration and repair of the damaged muscle. In contrast, a constitutive presence of ROS maintained by neutrophils develops into a pathological state which promotes muscle injury by damaging myoblasts and myotubes and by slowing muscle regeneration [36]. During inflammation, ROS generated as a result of the TNF $\alpha$ inflammatory cytokine action may prevent the formation of $\beta$-catenin-E-cadherin complexes in the vicinity of the cell membrane, thereby altering interactions between the cell and the extracellular matrix and between cells, thus inhibiting the formation of myotubes [57, 58].

ROS accumulation causes muscle atrophy and muscle weakness. In fact, aged muscles produce more ROS and
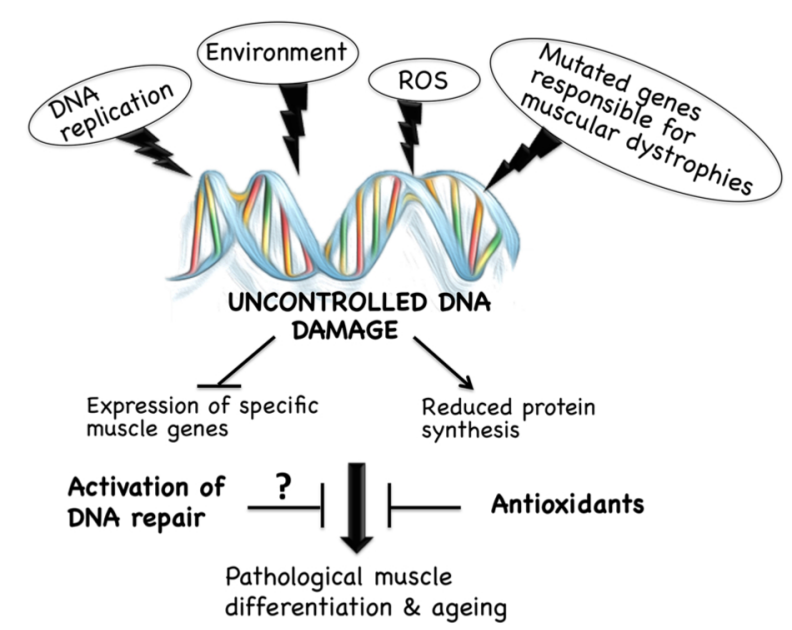
accumulate oxidative damage $[59,60]$. Muscle inactivity, most commonly seen in elderly people, causes local ROS production which might lead to muscle atrophy [61, 62]. In old muscles, antioxidant muscle adaptation to ROS production is diminished [63]. In addition, the accumulation of iron with age accelerates the production of ROS [64] Therefore, muscles become more susceptible to ROS with aging, which leads to an increased level of lipid oxidative degradation, protein oxidation and oxidative damage of DNA. A strong ROS production is accompanied by muscle fatigue and a decrease in muscle strength [35, 65].

To sum up, oxidative stress can severely affect myogenic differentiation and muscle regeneration by altering satellite cells proliferation, cell fusion and differentiation. It thus alters the morphology and function of skeletal muscle and accelerates muscle aging. ROS have been described to be involved in the pathophysiology of several muscle diseases, including DMD [120-122], myotonic dystrophy [123], LGMD dystrophy [124], FSHD [80] and sarcopenia [125]; antioxidants have been suggested as a treatment of muscle disease in dystrophic mouse models $[126,127]$ (discussed in the "Antioxidants in treatment of neuromuscular disorders" section).

\section{Oxidative DNA damage}

DNA damage plays a major role in mutagenesis, carcinogenesis, and aging. It may be either endogenous (i.e., due to respiration and cell metabolism) or exogenous. Several types of oxidative DNA damage are caused by ROS: simple DNA lesions (oxidized bases, abasic sites, etc.) and complex DNA lesions such as OCDL (non-DSB oxidative clustered bi-stranded DNA lesions) (for review, see [52]).

8 -Hydroxy-2'-deoxyguanosine $(8-\mathrm{OH}-\mathrm{dG})$ is the most abundant and most studied oxidative modification of DNA [53]. The 8-OH-dG is generated following guanosine hydroxylation and pairs preferably with adenine. When $8-\mathrm{OH}-\mathrm{dGs}$ are not eliminated, they can generate $\mathrm{GC} \rightarrow \mathrm{TA}$ transversions during DNA replication [54]. 8-OH-dG lesions are repaired primarily by the base excision repair (BER) pathway; this releases the base and creates an abasic site (AP site, for apurinic/apyrimidinic site) $[55,56]$.

ROS can also generate apurinic/apyrimidinic sites by capturing the hydrogen of deoxyriboses. Unrepaired AP sites can lead to the cleavage of the sugar-phosphate bond of the DNA backbone and cause DNA single-strand breaks (SSB) [57]. AP sites are frequently induced in the genome (50,000-200,000 injuries per mammalian cell) [58, 59]. However, in the presence of ROS their amount is largely increased [60] and their persistence causes deleterious effects. Indeed, AP sites may be transformed into SSB. Several SSBs close to each other on both strands of DNA can form double-strand breaks (DSBs). This effect is frequently caused by ionizing radiation (for review see [57]). DSBs are mutagenic when repaired by non-homologous end joining and have the potential to induce chromosomal translocations (reviewed in [61]. AP sites are also mutagenic due to the preferential incorporation of adenine on the opposite strand of the DNA during replication. To ensure the complementarity of bases, the AP site is thus replaced by a thymine nucleotide [62] (for review, see [63]).

\section{DNA damage response}

DNA damage response (DDR) is distinct, complex and functionally intertwined pathways for maintaining genome integrity. These pathways include coordinated process for the detection of DNA damage, the accumulation of DNA repair factors at the site of damage, and finally the physical repair of DNA damage. Each DNA repair mechanism is specific for one or more types of DNA damage [64]. Two major DNA damage detection pathways, ATM (Ataxia Telangiectasia Mutated) and ATR (ATM-related), are interconnected and regulate each other in response to different stimuli and different types of DNA damage (reviewed in [65]). These DDR pathways lead to a temporary cell cycle arrest, thus coordinating DNA repair. When DNA damage is excessive, apoptosis is triggered upon excessive DNA damage [66]. When lesions affect DNA bases and do not alter the double helix structure of DNA, such as 8-OH-dG, AP sites and $\mathrm{SSB}$, they are repaired via the BER pathway [56]. DNA mismatches induced by 8 -oxo-dG and AP sites are repaired by the mismatch repair (MMR) (for review see [67]). Two DDR pathways are responsible for DSB repair: the homologous recombination (HR) pathway that requires sister chromatid as a DNA template [68] and is thus considered as an error-free repair mechanism, and the non-homologous end joining (NHEJ) pathway, an error-prone repair process that can generate insertions or deletions [69].

DNA replication and transcription are also affected by DNA damage. Indeed, if replication bypasses DNA lesions, it can generate mutations and can, therefore, initiate carcinogenesis. If transcription is blocked by DNA damage, it causes senescence or apoptosis, thus accelerating cellular aging [1]. Thus, excessive ROS production, antioxidant deficiency or inefficient DNA damage detection or repair affect the level of oxidative modifications of DNA and, therefore, modulate the frequency of mutations and possibly cancer incidence $[63,70]$. 


\section{DNA damage, myogenic differentiation and muscle function}

DNA damage, as well as oxidative stress, affects myogenic differentiation of skeletal muscle cells. Several studies have demonstrated the transient presence of DNA breaks in the process of myogenic differentiation in vitro and during muscle regeneration in vivo $[71,72]$. Indeed, in skeletal muscle cells, the activation of the caspase-activated DNase (CAD) by caspase 3 during early stages of the myogenic differentiation results in controlled DNA cleavage and transient strand breaks formation. These controlled events are described as crucial to the myogenic differentiation progress, activating and targeting particular genes, e.g., by inducing DNA damage in the promoter of P21 cell cycle regulatory factor [73]. Coordinated DNA strand breaks are then rapidly repaired by the temporary caspase-triggered base excision repair pathway, as demonstrated by transient accumulation of XRCC1 repair foci in early myogenic differentiation [74]. Thus, as with the ROS, the transient and controlled DNA damage turns out to be "beneficial" for the muscle cells. For example, high doses of antioxidants which significantly reduced DNA damage also inhibited cell differentiation [75]. However, the excess and/ or constitutive presence of ROS negatively affects both myogenic differentiation and muscle function.

In post-mitotic differentiated cells which no longer replicate their genetic material, DNA repair mechanisms are generally attenuated and this leads to accumulation of DNA damage during and after myogenic differentiation. However, DNA repair remains active for genes highly expressed in differentiated cells, such as genes encoding structural proteins and functional enzymes, thereby protecting the integrity of these genes and the function of their products $[76,77]$.

DNA damage accumulated in myoblasts after genotoxic treatment inhibits the expression of specific muscle genes (myogenin and $M H C$ ) and blocks the formation of myotubes [78]. This "differentiation checkpoint" induced by DNA damage corresponded to the cell cycle arrest of myoblasts in G1 or in G2 phases. However, the myogenic differentiation checkpoint is reversible since withdrawal of the genotoxic agent leads to restoration of myogenic differentiation in vitro. This differentiation checkpoint delays global gene reprogramming associated with myogenic differentiation to allow DNA repair and most likely protects against the accumulation of DNA damage in differentiated myotubes, which can compromise genomic integrity of muscle fibers. Thus, the presence of DNA damage in muscle satellite cells may affect their capacity to regenerate damaged muscles. On the other hand, the presence of sustained DNA damage from prolonged and repeated exposure of myoblasts undergoing differentiation to genotoxic agents such as ionizing radiation led to the formation of giant multinucleated myotubes with distorted phenotype [78]. Thus, phenotypically abnormal myotubes may arise from the bypass of the differentiation checkpoint which can compromise muscle remodeling and function.

DNA damage and chromosomal aberrations were observed in the skeletal muscle tissue and primary myoblast cultures from patients with muscular dystrophies, such as facioscapulohumeral dystrophy (FSHD), Duchenne muscular dystrophy (DMD) and limb girdle muscular dystrophy (LGMD), resulting in the accumulation of $\gamma \mathrm{H} 2 \mathrm{AX}$ foci, a marker of DNA double-strand breaks [79-82].

DNA damage directly contributes to aging by repressing gene expression, or indirectly by inducing apoptosis or cellular senescence [83, 84]. Oxidative DNA damage seems to be the major type of DNA damage which appears with/during aging [85, 86]. Accumulation of oxidative damage in nuclear and mitochondrial DNA was observed in aged skeletal muscles of mice, rats and humans [87-89]. Oxidative DNA damage blocks transcription and reduces protein synthesis and degradation; an attenuated synthesis of key proteins such as actin and myosin weakens the muscle function and strength [90, 91].

\section{Mitochondrial DNA damage in aging and disease}

Accumulation of mitochondrial DNA (mtDNA) damage in muscles leads to sarcopenia, an age-related health problem that results in the loss of skeletal muscle function and mass (up to $50 \%$ by age 80 ) [92]. Mitochondrial DNA damage occurs at a higher level than nuclear DNA damage [93], due to a high rate of ROS production in mitochondria, the absence of histones which protect DNA molecule from damage and the absence of some types of DNA repair in mitochondria. Oxidative damage contributes to accumulation of mtDNA deletions and in particular of a "common deletion" or mtDNA4977 which occurs between two $13 \mathrm{bp}$ direct repeats that are separated by $4977 \mathrm{bp}$. The levels of mtDNA4977 were at least 100-fold higher in human skeletal and cardiac muscles from aged subjects $[92,94]$. Both the number and variety of mtDNA rearrangements increased dramatically with age [95]. This correlated with mtDNA oxidative damage and a decline in mitochondrial ATP production in skeletal muscles [88, 96].

As multiple copies of the mtDNA exist in the mitochondrial reticulum, both wild-type and mutant mtDNA coexist in a state of heteroplasmy. Thus, almost no effect of mutation is observed until mutant mtDNA reaches a certain 
fraction (a so-called "phenotypic threshold"). This threshold can be attained only after expansion of the mutation which appears in a single mtDNA molecule. This process called "clonal expansion" can occur without selection due to random genetic drift and nonselective increase of mtDNA replication which keeps the number of wild-type mtDNA copies constant [97]. Studies of clonal expansions of mtDNA mutations are particularly important for understanding age-related changes in skeletal muscles. Histological analysis using specific staining for the active mitochondrial cytochrome $c$ oxidase (COX) revealed rare distinctive COX-deficient fibers containing a large proportion of mutant mtDNA (typically with deletions) $[98,99]$. Each COX-deficient fiber contained one type of deletion while other deficient fibers contained different deletions, which clearly confirmed their clonal nature and indicated that expanded mutations caused most if not all of the observed COX defects. The proportion of COX-deficient fibers was typically less than $0.1 \%$ in young human muscles and increased $\sim 10$ times with age. At least in some cases, COX deficiency was followed by complete degeneration of the fiber via apoptosis and necrosis [99-101].

The age-related defects in mtDNA could be recapitulated in vivo in mice with a genetic modification of a proofreading exonuclease activity of mitochondrial polymerase gamma (polG) resulting in an error-prone "mutator" enzyme. The "mutator" (homozygous Polg ${ }^{\text {mut/mut }}$ knock-in) mice generates $10-20 \times 10^{-4}$ mutations per base pair of mtDNA; this is accompanied by multiple symptoms of premature aging, including dilated cardiomyopathy, thymic involution, testicular atrophy, sarcopenia, etc. [102, 103]. No signs of oxidative stress were detected in these studies; however, recent studies using more sensitive ROS assays have demonstrated oxidative stress in various tissues of the mutator mice [104]. Mitochondrial hydrogen peroxide level was similar in young "mutator" and control mice, but increased with age in "mutator" mice while remaining unchanged in the control. Furthermore, transgenic overexpression of mitochondria-targeted catalase has been shown to partially attenuate cardiomyopathy in the "mutator" mice [105]. Recently, it was shown that the mitochondria-targeted antioxidant 10-(6'-plastoquinonyl) decyltriphenylphosphonium (SkQ1) [106] diminished the expression of the oxidative stress markers, delayed development of aging-related pathologies and prolonged the lifespan of the "mutator" mice. All these findings suggest a link between prolonged accumulation of mtDNA mutations, ROS production and premature muscular aging.

\section{DNA damage in neuromuscular disorders}

The accumulation of $\gamma \mathrm{H} 2 \mathrm{AX}$ foci, a DNA double-strand breaks marker, and the appearance of aneusomia with age was observed in muscle tissue and primary myoblast cultures from patients with DMD and LGMD type 2B (LGMD2B). DNA damage was also detected in the nonaffected muscles of a DMD fetus and young DMD patients and was, therefore, considered to be an early event in this pathology [81]. In addition, disruption of genes responsible for muscular dystrophies (dystrophin gene for DMD, dysferlin gene for LGMD) in murine models was accompanied by DNA damage, $\gamma \mathrm{H} 2 \mathrm{AX}$ foci accumulation, genetic instability characterized by duplications and amplifications of oncogenes, activation of the DNA damage response pathway, and an increased susceptibility to develop sarcoma [81].

A deficiency in DNA damage repair has been reported in Emery-Dreifuss muscular dystrophy, disease caused by the mutation in genes encoding emerin or lamin $\mathrm{A} / \mathrm{C}$, and in several laminopathies caused by mutations in genes encoding proteins of the nuclear lamina. Indeed, mutations in the gene encoding lamin $\mathrm{A} / \mathrm{C}$, involved in DNA repair and maintenance of genome integrity, disrupt DNA damage response and repair mechanisms, leading to genomic instability and premature aging [107-109].

The presence of DNA damage prenatally and at birth has been described in skeletal muscles of a mouse model of spinal muscular atrophy (SMA), a genetic disorder characterized by progressive limb and trunk paralysis, muscle atrophy and motor neuron degeneration. An increase in DNA fragmentation was observed few days after birth, accompanied by cell death [110].

Recently, DNA damage and oxidative stress were shown to be involved in the pathophysiology of facio-scapulohumeral dystrophy (FSHD), one of the most common genetic myopathies characterized by a progressive and asymmetric weakening of a specific group of skeletal muscles, typically facial, shoulder girdle and upper arms muscles. FSHD is a multifactorial disease that results from the combination of genetic and epigenetic events mapped at the $4 \mathrm{q} 35$ locus [111]. These alterations lead to chromatin relaxation followed by overexpression of many $4 \mathrm{q} 35$ genes, notably $D U X 4$, the major actor in FSHD pathology. FSHD myoblasts derived from patients show a distinct transcription profile; they exhibit morphological differentiation defects and are sensitive to oxidative stress. We found that constitutive presence of oxidative DNA damage in in vitro cultured FSHD myoblasts is related to DUX4 expression and appearance of morphological defects in FSHD myotubes [80]. Moreover, we demonstrated that a 
high basal level of DNA damage resulted in the accelerated saturation of DNA repair machinery in FSHD [79].

\section{Antioxidants in treatment of neuromuscular disorders}

The consequences of DNA damage in muscle satellite cells and fibers are dual: the controlled DNA damage is necessary for muscle differentiation $[73,74]$ while ROS-induced DNA damage may lead to degeneration and aging of differentiated muscles $[78,88,112,113]$. DNA damage and ROS may also inhibit proliferation and differentiation of muscle satellite cells [78] (for review, see [4]). Since the most DNA damage is caused by ROS, treatment of muscle cells with antioxidants was proposed and tested. Application of antioxidants improved proliferation of muscle progenitor cells [114], myotubes formation [115], functioning of differentiated muscles $[116,117]$ and the capacity of muscle satellite cells to fuse and to regenerate damaged muscles [80, 91, 118]. Antioxidants also stimulated angiogenesis which can improve muscle regeneration after ischemia [119]. On the other hand, high doses of antioxidants inhibited normal muscle differentiation $[75,118]$. Whether specific treatment of DNA damage in in vivo injured muscles or muscles of patients with neuromuscular dystrophies could reverse the defective phenotype remains the subject of further studies.

\section{Conclusions}

DNA damage and oxidative stress seem to be closely linked and can affect myogenic differentiation, the morphology and function of skeletal muscle. ROS are involved in the pathophysiology of several muscle diseases, including DMD [120-122], myotonic dystrophy [123], LGMD dystrophy [124], FSHD [80] and sarcopenia [125]. The beneficial effect of antioxidant treatment on muscles was observed in dystrophic mouse models [126, 127].

Oxidative stress, inefficient or altered DNA repair, chronic inflammation, overtraining, inactivity and muscle injury are major causes of DNA damage in skeletal muscles. DNA damage accumulation can induce point mutations, deletions, translocations and illegitimate recombination [128-130]. Apoptosis can protect cells from cell transformation and malignancy; thus, programmed cell death could simultaneously be a secure alternative to preserve muscle health, and a reason for muscle atrophy and muscle regeneration exhaustion.

Common characteristics of certain muscular dystrophies suggest the involvement of DNA damage and genetic instability in the pathophysiology of these diseases and their susceptibility to developing cancer (for review, see [82]). Mutations in genes responsible for muscular dystrophies can lead to DNA damage, premature aging as well as cancer development. Further studies are needed to decipher the molecular pathways linking DNA damage, muscle atrophy, muscle aging and cancer in human muscular dystrophies.

Acknowledgements This research was supported by the MEGAFSHD Grant from the Association Française contre les Myopathies (AFM) to YSV and the Grant No. 16-54-16015 from the Russian Foundation for Basic Research to $\mathrm{BC}$ and VZ. VZ acknowledges the André Mazon fellowship from the French embassy in Russia. We thank Ms. Shirmoné Botha for critical reading of the manuscript.

\section{References}

1. Hoeijmakers JHJ (2009) DNA damage, aging, and cancer. N Engl J Med 361:1475-1485. doi:10.1056/NEJMra0804615

2. Lindahl T (1993) Instability and decay of the primary structure of DNA. Nature 362:709-715. doi:10.1038/362709a0

3. Murphy MP (2009) How mitochondria produce reactive oxygen species. Biochem J 417:1-13. doi:10.1042/BJ20081386

4. Barbieri E, Sestili P (2012) Reactive oxygen species in skeletal muscle signaling. J Signal Transduct 2012:982794. doi:10.1155/ 2012/982794

5. Vasilaki A, Jackson MJ (2013) Role of reactive oxygen species in the defective regeneration seen in aging muscle. Free Radic Biol Med 65:317-323. doi:10.1016/j.freeradbiomed.2013.07. 008

6. Powers SK, Ji LL, Kavazis AN, Jackson MJ (2011) Reactive oxygen species: impact on skeletal muscle. Compr Physiol 1:941-969. doi:10.1002/cphy.c100054

7. Lamb GD, Westerblad H (2011) Acute effects of reactive oxygen and nitrogen species on the contractile function of skeletal muscle. J Physiol 589:2119-2127. doi:10.1113/jphysiol.2010. 199059

8. Beckendorf L, Linke WA (2015) Emerging importance of oxidative stress in regulating striated muscle elasticity. J Muscle Res Cell Motil 36:25-36. doi:10.1007/s10974-014-9392-y

9. Gomez-Cabrera MC, Borras C, Pallardo FV et al (2005) Decreasing xanthine oxidase-mediated oxidative stress prevents useful cellular adaptations to exercise in rats. J Physiol 567:113-120. doi:10.1113/jphysiol.2004.080564

10. Zuo L, Christofi FL, Wright VP et al (2004) Lipoxygenasedependent superoxide release in skeletal muscle. J Appl Physiol 97:661-668. doi:10.1152/japplphysiol.00096.2004

11. Bedard K, Krause K-H (2007) The NOX family of ROS-generating NADPH oxidases: physiology and pathophysiology. Physiol Rev 87:245-313. doi:10.1152/physrev.00044.2005

12. Valko M, Leibfritz D, Moncol J et al (2007) Free radicals and antioxidants in normal physiological functions and human disease. Int J Biochem Cell Biol 39:44-84. doi:10.1016/j.biocel. 2006.07.001

13. Culotta VC, Yang M, O'Halloran TV (2006) Activation of superoxide dismutases: putting the metal to the pedal. Biochim Biophys Acta Mol Cell Res 1763:747-758. doi:10.1016/j. bbamcr.2006.05.003

14. Kirkman HN, Gaetani GF (2007) Mammalian catalase: a venerable enzyme with new mysteries. Trends Biochem Sci 32:44-50. doi:10.1016/j.tibs.2006.11.003 
15. Janero DR (1991) Therapeutic potential of vitamin $E$ in the pathogenesis of spontaneous atherosclerosis. Free Radic Biol Med 11:129-144. doi:10.1016/0891-5849(91)90193-7

16. El-Agamey A, Lowe GM, McGarvey DJ et al (2004) Carotenoid radical chemistry and antioxidant/pro-oxidant properties. Arch Biochem Biophys 430:37-48. doi:10.1016/j.abb.2004.03.007

17. Carr A, Frei B (1999) Does vitamin C act as a pro-oxidant under physiological conditions? FASEB J 13:1007-1024

18. Meister A, Anderson ME (1983) Glutathione. Annu Rev Biochem 52:711-760. doi:10.1146/annurev.bi.52.070183.003431

19. Taghiyar M, Darvishi L, Askari G et al (2013) The effect of vitamin $\mathrm{C}$ and $\mathrm{e}$ supplementation on muscle damage and oxidative stress in female athletes: a clinical trial. Int J Prev Med 4:S16-S23

20. Hampton MB, Kettle AJ, Winterbourn CC (1998) Inside the neutrophil phagosome: oxidants, myeloperoxidase, and bacterial killing. Blood 92:3007-3017

21. Hardbower DM, de Sablet T, Chaturvedi R, Wilson KT (2013) Chronic inflammation and oxidative stress: the smoking gun for helicobacter pylori-induced gastric cancer? Gut Microbes. doi: $10.4161 /$ gmic. 25583

22. Mlchlels C, Kfmacli J (1988) Use of the inhibition of enzymatic antioxidant systems in order to evaluate their physiological importance. Eur J Biochem 177:435-441

23. Hagen TM, Ingersoll RT, Lykkesfeldt J et al (1999) (R)-alphalipoic acid-supplemented old rats have improved mitochondrial function, decreased oxidative damage, and increased metabolic rate. FASEB J 13:411-418

24. Liu B, Chen Y, St. Clair DK (2008) ROS and p53: a versatile partnership. Free Radic Biol Med 44:1529-1535. doi:10.1016/j. freeradbiomed.2008.01.011

25. Klaunig JE, Xu Y, Isenberg JS et al (1998) The role of oxidative stress in chemical carcinogenesis. Environ Health Perspect 106(Suppl):289-295. doi:10.1289/ehp.98106s1289

26. Rudd SG, Valerie NCK, Helleday T (2016) Pathways controlling dNTP pools to maintain genome stability. DNA Repair (Amst) 44:193-204. doi:10.1016/j.dnarep.2016.05.032

27. Li J-M, Shah AM (2003) ROS generation by nonphagocytic NADPH oxidase: potential relevance in diabetic nephropathy. J Am Soc Nephrol 14:221S-226S. doi:10.1097/01.ASN 0000077406.67663.E7

28. Robertson RP, Harmon J, Tran PO et al (2003) Glucose toxicity in $\beta$-cells: type 2 diabetes, good radicals gone bad, and the glutathione connection. Diabetes 52:581-587. doi:10.2337/ diabetes.52.3.581

29. Butler R, Morris AD, Belch JJF et al (2000) Allopurinol normalizes endothelial dysfunction in type 2 diabetics with mild hypertension. Hypertension 35:746-751. doi:10.1161/01.HYP 35.3.746

30. Dikalov SI, Vitek MP, Mason RP (2004) Cupric-amyloid $\beta$ peptide complex stimulates oxidation of ascorbate and generation of hydroxyl radical. Free Radic Biol Med 36:340-347. doi:10.1016/j.freeradbiomed.2003.11.004

31. Allan Butterfield D, Castegna A, Lauderback CM, Drake J (2002) Evidence that amyloid beta-peptide-induced lipid peroxidation and its sequelae in Alzheimer's disease brain contribute to neuronal death. Neurobiol Aging 23:655-664. doi:10.1016/S0197-4580(01)00340-2

32. Gomez-Cabrera MC, Domenech E, Viña J (2008) Moderate exercise is an antioxidant: upregulation of antioxidant genes by training. Free Radic Biol Med 44:126-131. doi:10.1016/j. freeradbiomed.2007.02.001

33. Barton-Davis ER, Shoturma DI, Musaro A et al (1998) Viral mediated expression of insulin-like growth factor I blocks the aging-related loss of skeletal muscle function. Proc Natl Acad Sci USA 95:15603-15607. doi:10.1073/pnas.95.26.15603
34. Reid MB (2001) Invited Review: redox modulation of skeletal muscle contraction: what we know and what we don't. J Appl Physiol 90:724-731. doi:10.1152/japplphysiol.00017.2004

35. Powers S, Jackson M (2008) Exercise-induced oxidative stress: cellular mechanisms and impact on muscle force production. Physiol Rev 88:1243-1276. doi:10.1152/physrev.00031.2007

36. Tidball JG (2005) Inflammatory processes in muscle injury and repair. Am J Physiol Regul Integr Comp Physiol 288:R345R353. doi:10.1152/ajpregu.00454.2004

37. Irrcher I, Ljubicic V, Hood DA (2009) Interactions between ROS and AMP kinase activity in the regulation of PGC-1alpha transcription in skeletal muscle cells. Am J Physiol Cell Physiol 296:C116-C123. doi:10.1152/ajpcell.00267.2007

38. Musarò A, Fulle S, Fanò G (2010) Oxidative stress and muscle homeostasis. Curr Opin Clin Nutr Metab Care 13:236-242. doi:10.1097/MCO.0b013e3283368188

39. Choi CS, Befroy DE, Codella R et al (2008) Paradoxical effects of increased expression of PGC-1alpha on muscle mitochondrial function and insulin-stimulated muscle glucose metabolism. Proc Natl Acad Sci USA 105:19926-19931. doi:10.1073/pnas. 0810339105

40. Kang C, O’Moore KM, Dickman JR, Ji LL (2009) Exercise activation of muscle peroxisome proliferator-activated receptor$\gamma$ coactivator- $1 \alpha$ signaling is redox sensitive. Free Radic Biol Med 47:1394-1400. doi:10.1016/j.freeradbiomed.2009.08.007

41. Kelly DP, Scarpulla RC (2004) Transcriptional regulatory circuits controlling mitochondrial biogenesis and function. Genes Dev 18:357-368. doi:10.1101/gad.1177604

42. Laplante M, Sabatini DM (2012) MTOR signaling in growth control and disease. Cell 149:274-293. doi:10.1016/j.cell.2012. 03.017

43. Bentzinger CF, Romanino K, Cloëtta D et al (2008) Skeletal muscle-specific ablation of raptor, but not of rictor, causes metabolic changes and results in muscle dystrophy. Cell Metab 8:411-424. doi:10.1016/j.cmet.2008.10.002

44. Mitsuishi M, Miyashita K, Muraki A et al (2013) Dietary protein decreases exercise endurance through rapamycin-sensitive suppression of muscle mitochondria. Am J Physiol Endocrinol Metab 305:E776-E784. doi:10.1152/ajpendo.00145.2013

45. Ruetenik A, Barrientos A (2015) Dietary restriction, mitochondrial function and aging: from yeast to humans. Biochim Biophys Acta 1847:1434-1447. doi:10.1016/j.bbabio.2015.05. 005

46. Li M, Zhao L, Liu J et al (2010) Multi-mechanisms are involved in reactive oxygen species regulation of mTORC1 signaling. Cell Signal 22:1469-1476. doi:10.1016/j.cellsig.2010.05.015

47. Sarbassov DD, Sabatini DM (2005) Redox regulation of the nutrient-sensitive raptor-mTOR pathway and complex. J Biol Chem 280:39505-39509. doi:10.1074/jbc.M506096200

48. Yoshida S, Hong S, Suzuki T et al (2011) Redox regulates mammalian target of rapamycin complex 1 (mTORC1) activity by modulating the TSC1/TSC2-Rheb GTPase pathway. J Biol Chem 286:32651-32660. doi:10.1074/jbc.M111.238014

49. Budanov AV, Sablina A, Feinstein E et al (2004) Regeneration of peroxiredoxins by p53-regulated sestrins, homologs of bacterial AhpD. Science 304:596-600. doi:10.1126/science. 1095569

50. Kim H, An S, Ro S-H et al (2015) Janus-faced Sestrin 2 controls ROS and mTOR signalling through two separate functional domains. Nat Commun 6:10025. doi:10.1038/ncomms 10025

51. Ding B, Parmigiani A, Divakaruni AS et al (2016) Sestrin2 is induced by glucose starvation via the unfolded protein response and protects cells from non-canonical necroptotic cell death. Sci Rep 6:22538. doi:10.1038/srep22538 
52. Nikitaki Z, Hellweg CE, Georgakilas AG, Ravanat J-L (2015) Stress-induced DNA damage biomarkers: applications and limitations. Front Chem 3:35. doi:10.3389/fchem.2015.00035

53. Beckman KB, Ames BN (1997) Oxidative decay of DNA. J Biol Chem 272:19633-19636. doi:10.1074/jbc.272.32.19633

54. Yasui M, Kanemaru Y, Kamoshita N et al (2014) Tracing the fates of site-specifically introduced DNA adducts in the human genome. DNA Repair (Amst) 15:11-20. doi:10.1016/j.dnarep. 2014.01.003

55. Demple B, Harrison L (1994) Repair of oxidative damage to DNA: enzymology and biology. Annu Rev Biochem 63:915-948. doi:10.1146/annurev.biochem.63.1.915

56. Almeida KH, Sobol RW (2007) A unified view of base excision repair: lesion-dependent protein complexes regulated by posttranslational modification. DNA Repair (Amst) 6:695-711. doi:10.1016/j.dnarep.2007.01.009

57. Breen AP, Murphy JA (1995) Reactions of oxyl radicals with DNA. Free Radic Biol Med 18:1033-1077. doi:10.1016/08915849(94)00209-3

58. Nakamura J, Swenberg JA (1999) Endogenous apurinic/ apyrimidinic sites in genomic DNA of mammalian tissues. Cancer Res 59:2522-2526

59. De Bont R (2004) Endogenous DNA damage in humans: a review of quantitative data. Mutagenesis 19:169-185. doi:10. 1093/mutage/geh025

60. Nakamura J, La DK, Swenberg JA (2000) 5'-nicked apurinic/ apyrimidinic sites are resistant to beta-elimination by betapolymerase and are persistent in human cultured cells after oxidative stress. J Biol Chem 275:5323-5328

61. Iarovaia OV, Rubtsov M, Ioudinkova E et al (2014) Dynamics of double strand breaks and chromosomal translocations. Mol Cancer 13:249. doi:10.1186/1476-4598-13-249

62. Obeid S, Blatter N, Kranaster R et al (2010) Replication through an abasic DNA lesion: structural basis for adenine selectivity. EMBO J 29:1738-1747. doi:10.1038/emboj.2010.64

63. Jackson AL, Loeb LA (2001) The contribution of endogenous sources of DNA damage to the multiple mutations in cancer. Mutat Res Fundam Mol Mech Mutagen 477:7-21. doi:10.1016/ S0027-5107(01)00091-4

64. Hoeijmakers JHJ (2001) DNA repair mechanisms. Maturitas 38:17-22

65. Yan S, Sorrell M, Berman Z (2014) Functional interplay between ATM/ATR-mediated DNA damage response and DNA repair pathways in oxidative stress. Cell Mol Life Sci 71:3951-3967. doi:10.1007/s00018-014-1666-4

66. Bernstein C, Bernstein H, Payne CM, Garewal H (2002) DNA repair/pro-apoptotic dual-role proteins in five major DNA repair pathways: fail-safe protection against carcinogenesis. Mutat Res Rev Mutat Res 511:145-178. doi:10.1016/S13835742(02)00009-1

67. Jiricny J (2006) The multifaceted mismatch-repair system. Nat Rev Mol Cell Biol 7:335-346. doi:10.1038/nrm1907

68. Moynahan ME, Jasin M (2010) Mitotic homologous recombination maintains genomic stability and suppresses tumorigenesis. Nat Rev Mol Cell Biol 11:196-207. doi:10.1038/ nrm2851

69. van Gent DC, van der Burg M (2007) Non-homologous endjoining, a sticky affair. Oncogene 26:7731-7740. doi:10.1038/sj. onc. 1210871

70. Epe B (2002) Role of endogenous oxidative DNA damage in carcinogenesis: what can we learn from repair-deficient mice? Biol Chem 383:467-475. doi:10.1515/BC.2002.049

71. Dawson BA, Lough J (1988) Immunocytochemical localization of transient DNA strand breaks in differentiating myotubes using in situ nick-translation. Dev Biol 127:362-367. doi:10. 1016/0012-1606(88)90322-3
72. Coulton GR, Rogers B, Strutt P et al (1992) In situ localisation of single-stranded DNA breaks in nuclei of a subpopulation of cells within regenerating skeletal muscle of the dystrophic mdx mouse. J Cell Sci 102(Pt 3):653-662

73. Larsen BD, Rampalli S, Burns LE et al (2010) Caspase 3/caspase-activated DNase promote cell differentiation by inducing DNA strand breaks. Proc Natl Acad Sci USA 107:4230-4235. doi:10.1073/pnas.0913089107

74. Al-Khalaf MH, Blake LE, Larsen BD et al (2016) Temporal activation of XRCC1-mediated DNA repair is essential for muscle differentiation. Cell Discov 2:15041. doi:10.1038/ celldisc. 2015.41

75. Zakharova VV, Dib C, Saada YB et al (2016) Uncoupling of oxidative phosphorylation and antioxidants affect fusion of primary human myoblasts in vitro. Biopolym Cell 32:111-117. doi: $10.7124 / \mathrm{bc} .000913$

76. Ho L, Hanawalt PC (1991) Gene-specific DNA repair in terminally differentiating rat myoblasts. Mutat Res Repair 255:123-141. doi:10.1016/0921-8777(91)90047-S

77. Nouspikel T, Hanawalt PC (2002) DNA repair in terminally differentiated cells. DNA Repair (Amst) 1:59-75. doi:10.1016/ S1568-7864(01)00005-2

78. Puri PL, Bhakta K, Wood LD et al (2002) A myogenic differentiation checkpoint activated by genotoxic stress. Nat Genet 32:585-593. doi:10.1038/ng 1023

79. Bou Saada Y, Dib C, Dmitriev P et al (2016) Facioscapulohumeral dystrophy myoblasts efficiently repair moderate levels of oxidative DNA damage. Histochem Cell Biol 145:475-483. doi:10.1007/s00418-016-1410-2

80. Dmitriev P, Bou Saada Y, Dib C et al (2016) DUX4-induced constitutive DNA damage and oxidative stress contribute to aberrant differentiation of myoblasts from FSHD patients. Free Radic Biol Med 99:244-258. doi:10.1016/j.freeradbiomed.2016. 08.007

81. Schmidt WM, Uddin MH, Dysek S et al (2011) DNA damage, somatic aneuploidy, and malignant sarcoma susceptibility in muscular dystrophies. PLoS Genet 7:e1002042. doi:10.1371/ journal.pgen.1002042

82. Fanzani A, Monti E, Donato R, Sorci G (2013) Muscular dystrophies share pathogenetic mechanisms with muscle sarcomas. Trends Mol Med 19:546-554. doi:10.1016/j.molmed.2013.07. 001

83. Best BP (2009) Nuclear DNA damage as a direct cause of aging. Rejuvenation Res 12:199-208. doi:10.1089/rej.2009.0847

84. Freitas AA, De Magalhães JP (2011) A review and appraisal of the DNA damage theory of ageing. Mutat Res Rev Mutat Res 728:12-22. doi:10.1016/j.mrrev.2011.05.001

85. Ishchenko A, Sinitsyna O, Krysanova Z et al (2003) Age-dependent increase of 8-oxoguanine-, hypoxanthine-, and uracilDNA glycosylase activities in liver extracts from OXYS rats with inherited overgeneration of free radicals and Wistar rats. Med Sci Monit 9:BR16-BR24

86. Sinha JK, Ghosh S, Swain U et al (2014) Increased macromolecular damage due to oxidative stress in the neocortex and hippocampus of WNIN/Ob, a novel rat model of premature aging. Neuroscience 269:256-264. doi:10.1016/j.neuroscience. 2014.03.040

87. Hamilton ML, Van Remmen H, Drake JA et al (2001) Does oxidative damage to DNA increase with age? Proc Natl Acad Sci USA 98:10469-10474. doi:10.1073/pnas.171202698

88. Short KR, Bigelow ML, Kahl J et al (2005) Decline in skeletal muscle mitochondrial function with aging in humans. Proc Natl Acad Sci USA 102:5618-5623. doi:10.1073/pnas.0501559102

89. Mecocci P, Fanó G, Fulle S et al (1999) Age-dependent increases in oxidative damage to DNA, lipids, and proteins in 
human skeletal muscle. Free Radic Biol Med 26:303-308. doi:10.1016/S0891-5849(98)00208-1

90. Piec I, Listrat A, Alliot J et al (2005) Differential proteome analysis of aging in rat skeletal muscle. FASEB J 19:1143-1145. doi:10.1096/fj.04-3084fje

91. Vermeij WP, Hoeijmakers JHJ, Pothof J (2016) Genome integrity in aging: human syndromes, mouse models, and therapeutic options. Annu Rev Pharmacol Toxicol 56:427-445. doi:10.1146/annurev-pharmtox-010814-124316

92. Cortopassi GA, Arnheim N (1990) Detection of a specific mitochondrial DNA deletion in tissues of older humans. Nucleic Acids Res 18:6927-6933

93. Richter C, Park JW, Ames BN (1988) Normal oxidative damage to mitochondrial and nuclear DNA is extensive. Proc Natl Acad Sci USA 85:6465-6467

94. Cortopassi GA, Shibata D, Soong NW, Arnheim N (1992) A pattern of accumulation of a somatic deletion of mitochondrial DNA in aging human tissues. Proc Natl Acad Sci USA 89:7370-7374

95. Melov S, Shoffner JM, Kaufman A, Wallace DC (1995) Marked increase in the number and variety of mitochondrial DNA rearrangements in aging human skeletal muscle. Nucleic Acids Res 23:4122-4126

96. Khrapko K, Vijg J (2009) Mitochondrial DNA mutations and aging: devils in the details? Trends Genet 25:91-98. doi:10. 1016/j.tig.2008.11.007

97. Khrapko K, Turnbull D (2014) Mitochondrial DNA mutations in aging. Prog Mol Biol Transl Sci 27:29-62

98. Wanagat J, Cao Z, Pathare P, Aiken JM (2001) Mitochondrial DNA deletion mutations colocalize with segmental electron transport system abnormalities, muscle fiber atrophy, fiber splitting, and oxidative damage in sarcopenia. FASEB J 15:322-332. doi:10.1096/fj.00-0320com

99. Herbst A, Pak JW, McKenzie D et al (2007) Accumulation of mitochondrial DNA deletion mutations in aged muscle fibers: evidence for a causal role in muscle fiber loss. J Gerontol A Biol Sci Med Sci 62:235-245

100. Marzetti E, Hwang JCY, Lees HA et al (2010) Mitochondrial death effectors: relevance to sarcopenia and disuse muscle atrophy. Biochim Biophys Acta Gen Subj 1800:235-244. doi:10.1016/j.bbagen.2009.05.007

101. Cheema N, Herbst A, McKenzie D, Aiken JM (2015) Apoptosis and necrosis mediate skeletal muscle fiber loss in age-induced mitochondrial enzymatic abnormalities. Aging Cell 14:1085-1093. doi:10.1111/acel.12399

102. Trifunovic A, Wredenberg A, Falkenberg M et al (2004) Premature ageing in mice expressing defective mitochondrial DNA polymerase. Nature 429:417-423. doi:10.1038/nature02517

103. Kujoth GC, Hiona A, Pugh TD et al (2005) Mitochondrial DNA mutations, oxidative stress, and apoptosis in mammalian aging. Science 309:481-484. doi:10.1126/science.1112125

104. Kolesar JE, Safdar A, Abadi A et al (2014) Defects in mitochondrial DNA replication and oxidative damage in muscle of mtDNA mutator mice. Free Radic Biol Med 75:241-251. doi:10.1016/j.freeradbiomed.2014.07.038

105. Dai D-F, Chen T, Wanagat J et al (2010) Age-dependent cardiomyopathy in mitochondrial mutator mice is attenuated by overexpression of catalase targeted to mitochondria. Aging Cell 9:536-544. doi:10.1111/j.1474-9726.2010.00581.x

106. Skulachev VP, Anisimov VN, Antonenko YN et al (2009) An attempt to prevent senescence: a mitochondrial approach. Biochim Biophys Acta Bioenerg 1787:437-461. doi:10.1016/j. bbabio.2008.12.008

107. Liu B, Wang J, Chan KM et al (2005) Genomic instability in laminopathy-based premature aging. Nat Med 11:780-785. doi:10.1038/nm 1266
108. Capell BC, Collins FS (2006) Human laminopathies: nuclei gone genetically awry. Nat Rev Genet 7:940-952. doi:10.1038/ nrg 1906

109. Camozzi D, Capanni C, Cenni V et al (2014) Diverse lamindependent mechanisms interact to control chromatin dynamics: focus on laminopathies. Nucleus 5:1-14. doi:10.4161/nucl. 36289

110. Fayzullina S, Martin LJ (2014) Skeletal muscle DNA damage precedes spinal motor neuron DNA damage in a mouse model of spinal muscular atrophy (SMA). PLoS One. doi:10.1371/journal. pone.0093329

111. Dmitriev P, Lipinski M, Vassetzky YS (2009) Pearls in the junk: dissecting the molecular pathogenesis of facioscapulohumeral muscular dystrophy. Neuromuscul Disord 19:17-20. doi:10. 1016/j.nmd.2008.09.004

112. Powers SK, Kavazis AN, DeRuisseau KC (2005) Mechanisms of disuse muscle atrophy: role of oxidative stress. Am J Physiol Regul Integr Comp Physiol 288:R337-R344. doi:10.1152/ ajpregu.00469.2004

113. Powers SK, Kavazis AN, McClung JM (2007) Oxidative stress and disuse muscle atrophy. J Appl Physiol 102:2389-2397. doi:10.1152/japplphysiol.01202.2006

114. Togliatto G, Trombetta A, Dentelli P et al (2013) Unacylated ghrelin promotes skeletal muscle regeneration following hindlimb ischemia via SOD-2-mediated miR-221/222 expression. J Am Hear Assoc 2:e000376. doi:10.1161/JAHA.113.000376

115. Hidalgo M, Marchant D, Quidu P et al (2014) Oxygen modulates the glutathione peroxidase activity during the L6 myoblast early differentiation process. Cell Physiol Biochem 33:67-77. doi:10.1159/000356650

116. Kim JH, Lawler JM (2012) Amplification of proinflammatory phenotype, damage, and weakness by oxidative stress in the diaphragm muscle of $\mathrm{mdx}$ mice. Free Radic Biol Med 52:1597-1606. doi:10.1016/j.freeradbiomed.2012.01.015

117. Selsby JT (2011) Increased catalase expression improves muscle function in mdx mice. Exp Physiol 96:194-202. doi:10.1113/ expphysiol.2010.054379

118. Bosutti A, Degens H (2015) The impact of resveratrol and hydrogen peroxide on muscle cell plasticity shows a dose-dependent interaction. Sci Rep 5:8093. doi:10.1038/srep08093

119. Jazwa A, Stepniewski J, Zamykal M et al (2013) Pre-emptive hypoxia-regulated HO-1 gene therapy improves post-ischaemic limb perfusion and tissue regeneration in mice. Cardiovase Res 97:115-124. doi:10.1093/cvr/cvs284

120. Murphy ME, Kehrer JP (1986) Activities of antioxidant enzymes in muscle, liver and lung of chickens with inherited muscular dystrophy. Biochem Biophys Res Commun 134:550-556. doi:10.1016/S0006-291X(86)80455-7

121. Messina S, Altavilla D, Aguennouz M et al (2006) Lipid peroxidation inhibition blunts nuclear factor- $\kappa \mathrm{B}$ activation, reduces skeletal muscle degeneration, and enhances muscle function in mdx mice. Am J Pathol 168:918-926. doi:10.2353/ajpath.2006. 050673

122. Rodriguez MC, Tarnopolsky MA (2003) Patients with dystrophinopathy show evidence of increased oxidative stress. Free Radic Biol Med 34:1217-1220. doi:10.1016/S08915849(03)00141-2

123. Toscano A, Messina S, Campo GM et al (2005) Oxidative stress in myotonic dystrophy type 1. Free Radic Res 39:771-776. doi:10.1080/10715760500138932

124. Haslbeck KM, Friess U, Schleicher ED et al (2005) The RAGE pathway in inflammatory myopathies and limb girdle muscular dystrophy. Acta Neuropathol 110:247-254. doi:10.1007/s00401005-1043-3

125. Fulle S, Fanò G (2007) The contribution of reactive oxygen species in sarcopenia and muscle aging. Role Phys Exerc Prev 
Dis Improv Qual Life 39:103-111. doi:10.1007/978-88-4700376-7_6

126. Dorchies OM, Wagner S, Vuadens O et al (2006) Green tea extract and its major polyphenol (-)-epigallocatechin gallate improve muscle function in a mouse model for Duchenne muscular dystrophy. Am J Physiol Cell Physiol 290:C616C625. doi:10.1152/ajpcell.00425.2005

127. Burdi R, Rolland J-F, Fraysse B et al (2009) Multiple pathological events in exercised dystrophic mdx mice are targeted by pentoxifylline: outcome of a large array of in vivo and ex vivo tests. J Appl Physiol 106:1311-1324. doi:10.1152/japplphysiol. 90985.2008

128. Ferguson DO, Alt FW (2001) DNA double strand break repair and chromosomal translocation: lessons from animal models. Oncogene 20:5572-5579. doi:10.1038/sj.onc. 1204767

129. Helleday T (2003) Pathways for mitotic homologous recombination in mammalian cells. Mutat Res 532:103-115

130. Knoch J, Kamenisch Y, Kubisch C, Berneburg M (2012) Rare hereditary diseases with defects in DNA-repair. Eur J Dermatol 22:443-455. doi:10.1684/ejd.2012.1654 